\title{
Keterbatasan radiografi panoramik dalam pengukuran ketidaksimetrisan mandibula
}

\author{
Barunawaty Yunus \\ Bagian Radiologi \\ Fakultas Kedokteran Gigi Universitas Hasasanuddin
}

\begin{abstract}
Panoramic radiography is a technique to yield face structure photo including bone of maxilla, mandible and supporting structures like maxilla antrum, nasal fossa, TMJ, procesus styloideus, and os. hyoid. Panoramic radiography is also used to evaluate asymmetrical of face. Growth and development of head is similar to the growth and development of body in general. The skeletal morphology can be disturbed by internal disorder of TMJ and degenerative joint disease as short ramus, a sharp angle of mandible, and also cranial base that cause asymmetrical face. By taking accurate panoramic radiography, the mandible asymmetrical can be measured.
\end{abstract}

Key words: panoramic radiography, maxilla, mandible

\begin{abstract}
ABSTRAK
Radiografi panoramik adalah suatu teknik untuk menghasilkan foto struktur wajah termasuk tulang maksila, mandibula dan struktur-struktur pendukungnya seperti antrum maksila, fossa nasalis, sendi temporomandibula, prosesus stiloideus, dan os. hyoid. Radiografi panoramik juga digunakan untuk mengevaluasi ketidaksimetrisan wajah. Pertumbuhan dan perkembangan kepala sama dengan pertumbuhan dan perkembangan tubuh pada umumnya. Morfologi skeletal dapat terganggu akibat gangguan internal dari sendi tempooromandibula dan penyakit degeneratif sendi, demikian pula dengan ramus yang pendek, sudut dataran mandibula yang tinggi, serta basis kranial yang menyebabkan muka menjadi tidak simetris. Dengan melakukan pemeriksaan radiografi panoramik, maka dapat diketahui keakuratan radiografi panoramik dalam mengukur ketidaksimetrisan mandibula.
\end{abstract}

Kata kunci: radiografi panoramik, maksila, mandibula 
Koresponden : Barunawaty Yunus, J1.Sunu M17, Makassar, Indonesia. E-mail: barunawaty@yahoo.com

\section{PENDAHULUAN}

Pola pertumbuhan dan perkembangan kepala sama dengan pertumbuhan dan perkembangan tubuh pada umumnya. Meskipun demikian, tulangtulang kepala mempunyai pusat pertumbuhan tersendiri, kadang ada yang pertumbuhannya cepat dan ada yang lambat. Morfologi skeletal dapat terganggu akibat gangguan internal pada sendi temporomandibula dan penyakit degeneratif sendi, demikian pula dengan ramus yang pendek, sudut bidang mandibula yang tinggi, serta cranial base yang melibatkan pergeseran diskus yang salah dan rheumatoid arthritis. Faktor-faktor tersebut yang kadang menyebabkan muka menjadi tidak simetris. 1

Adapun teknik radiografi yang paling sering digunakan untuk mengevaluasi ketidaksimetrisan wajah antara lain melalui pencitraan panoramik.2 Karena radiografi panoramik dapat memberikan gambaran maksila dan mandibula secara bilateral, termasuk sendi temporomandibula dan struktur tulang sekitarnya, teknik ini banyak digunakan dalam berbagai jenis perawatan kedokteran gigi.1
Penulisan makalah ini bertujuan untuk memberikan pemahaman tentang keterbatasan radiografi panoramik dalam pengukuran ketidaksimetrisan mandibula.

\section{TINJAUAN PUSTAKA}

Pencitraan panoramik yang disebut juga pantomografi merupakan teknik untuk menghasilkan gambaran tunggal tomografi struktur wajah meliputi kedua arkus gigi maksila dan mandibula dan struktur pendukungnya (gambar 1). Prinsip kerja pantomografi adalah pergerakan resiprokal dari sumber sinar-x dan reseptor gambar mengelilingi titik atau bidang pusat, yang disebut image layer, tempat objek berada. Bila objek berada di depan atau belakang image layer ini, maka gambar yang ditangkap tidak jelas karena pergerakan relatifnya terhadap pusat rotasi dari reseptor dan sumber sinar-x.2

Radiografi panoramik telah digunakan secara luas untuk memperoleh suatu gambaran yang menyeluruh dari struktur maksilofasial yang kompleks.3 Sebagaimana pada semua interpretasi radiografi maka inti radiografi panoramik adalah pendekatan sistematis untuk 
menganalisis gambar dan memahami tampilan dari struktur anatomi normal pada radiografi. Gambaran panoramik sedikit berbeda dari gambaran intraoral yang berpusat pada pendekatan interpretasinya. Mengenali struktur anatomi normal pada radiografi panoramik dapat memberikan tantangan karena anatomi yang rumit dari midfasial, superimposisi dari berbagai struktur anatomi dan perubahan proyeksi orientasi.2
Gambar panoramik utamanya merupakan 3 gambar dalam 1 gambar, yaitu gambaran posterolateral kanan dan kiri sampai gigi kaninus, gambaran anterior, dan gambaran posteroanterior terhadap gigi kaninus. Tampilan struktur anatomi yang penting dari mandibula pada gambaran panoramik adalah prosesus kondiloideus dan sendi temporomandibula, prosesus koronoideus, ramus, korpus dan sudut, sekstan anterior, gigi dan struktur pendukungnya. 2

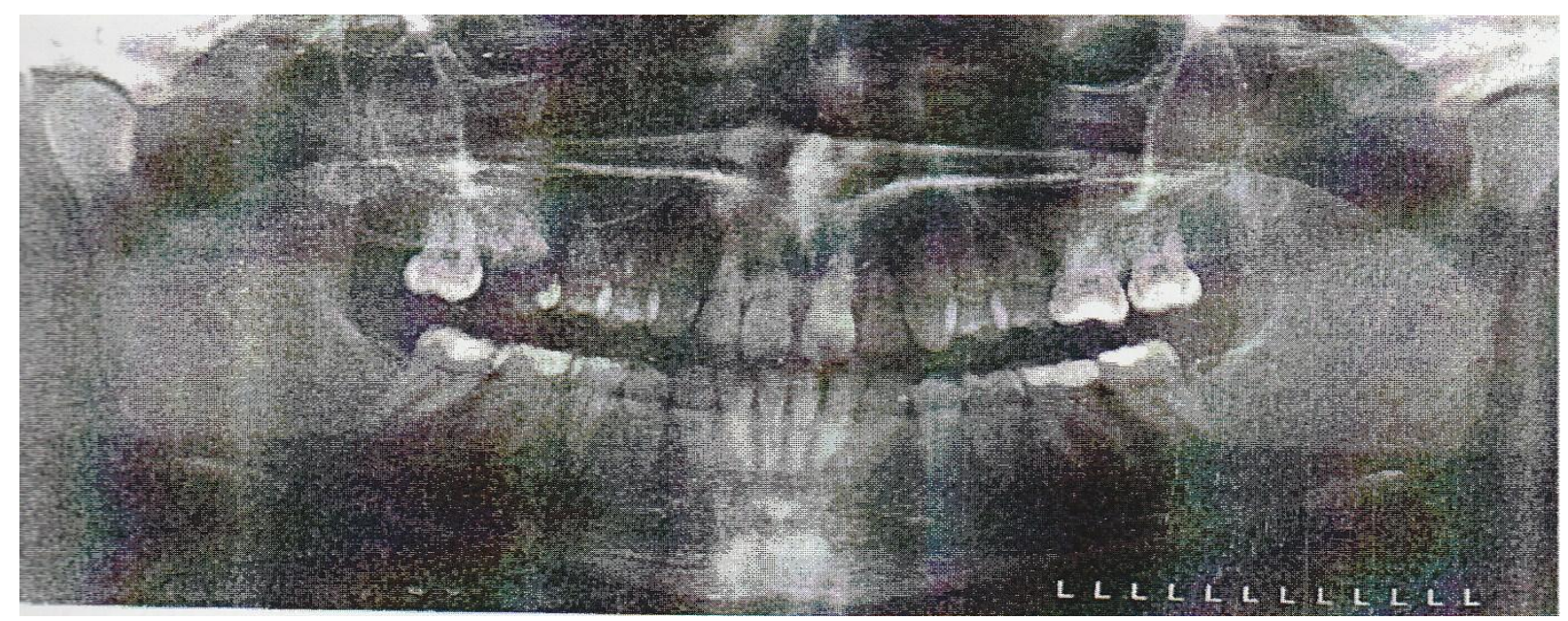

Gambar 1. Gambaran panoramik maksila, mandibula dan gigi-geligi

Evaluasi proporsi wajah yang seimbang adalah jarak trichion ke glabella kurang lebih sama dengan jarak dari glabella ke subnasion, dan jarak dari subnasion ke gnation. Pada wajah bagian bawah, sudut mulut terletak $1 / 3$ jarak hidung ke dagu, dan supramental terletak $2 / 3$ dari daerah hidung ke dagu. 2

Ketidaksimetrisan wajah dicirikan dengan (1) perubahan midline relatif dari satu atau kedua rahang terhadap bidang midsagital cranial, dan (2) perbedaan tinggi dimensi rahang dibanding ciri-ciri yang telah disebutkan. Ketidaksimetrisan wajah karena faktor skeletal paling sering terjadi akibat pertumbuhan wajah yang berlebih atau kurang secara unilateral.4

Hubungan antara gangguan sendi temporomandibula dan ketidaksimetrisan wajah tampak pada ketidaksimetrisan mandibula yang merupakan perkembangan sekunder dari pergeseran sendi yang salah. 
Pergeseran sendi temporomandibula yang salah pada usia dini mengindikasikan terjadinya perubahan osteoartrosis sekunder, dengan hilangnya massa kondil pada kemudian hari.4

Beberapa penelitian terdahulu telah menguji kemampuan radiografi panoramik untuk menilai keakuratan dalam hal pengukuran anatomi. Salah satu di antaranya adalah penelitian yang dilakukan Ludlow JB dkk, yang menggunakan tulang tengkorak kering atau model mandibula dalam hal penilaian keakuratan radiografi panoramik untuk berbagai pengukuran, meskipun semua gambaran panoramik dilakukan dengan unit panoramik Orthophos Plus (Sirona, Charlotte NC). 5

Pada penelitian tersebut, mandibula terkunci pada posisi intercusp secara maksimal dan gambar panoramik dibuat pada tulang tengkorak. Suatu posisi ideal (gambar 2) ditentukan menggunakan latar garis midsagital di atas atap tengkorak serta tiga titik yang dibuat pada nasion, spina nasalis anterior, dan pogonion. Landmark tersebut dipusatkan pada acuan subposisi subnasal dan sinar dari unit sinar-x diposisikan vertikal. Unit sinar-x yang diposisikan horisontal digunakan untuk mensejajarkan porion dan orbital pada satu posisi bidang horisontal frankfurt dengan tinggi yang sama.5

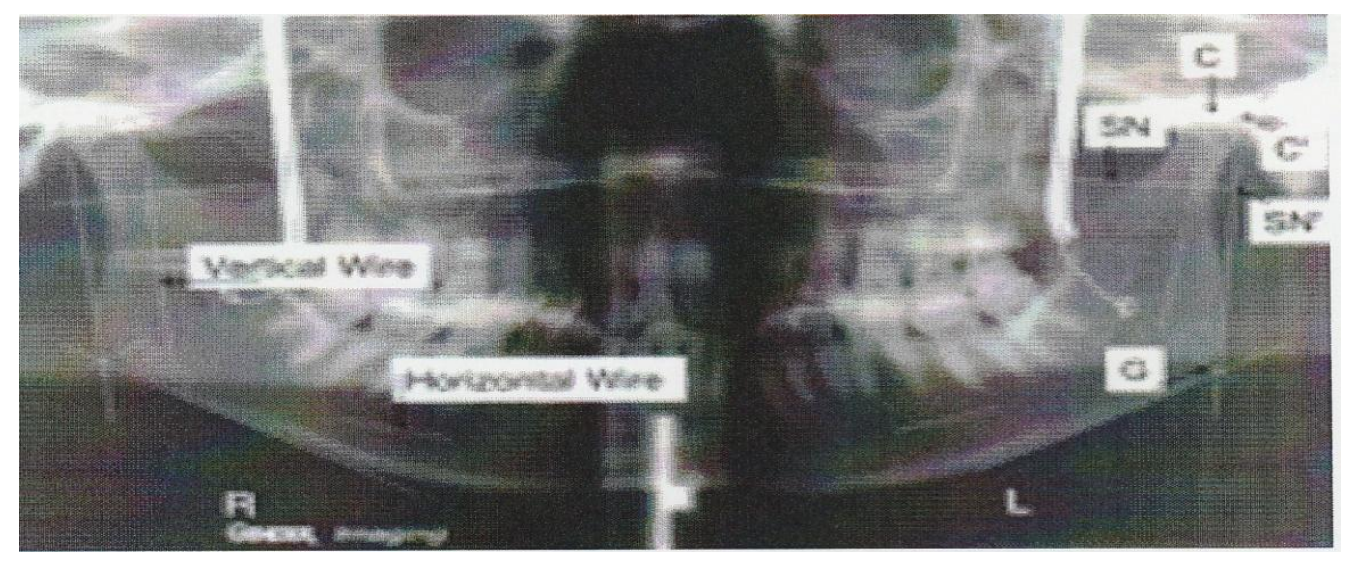

Gambar 2. Gambar panoramik dari tengkorak dalam posisi ideal, ditandai untuk pengukuran. 


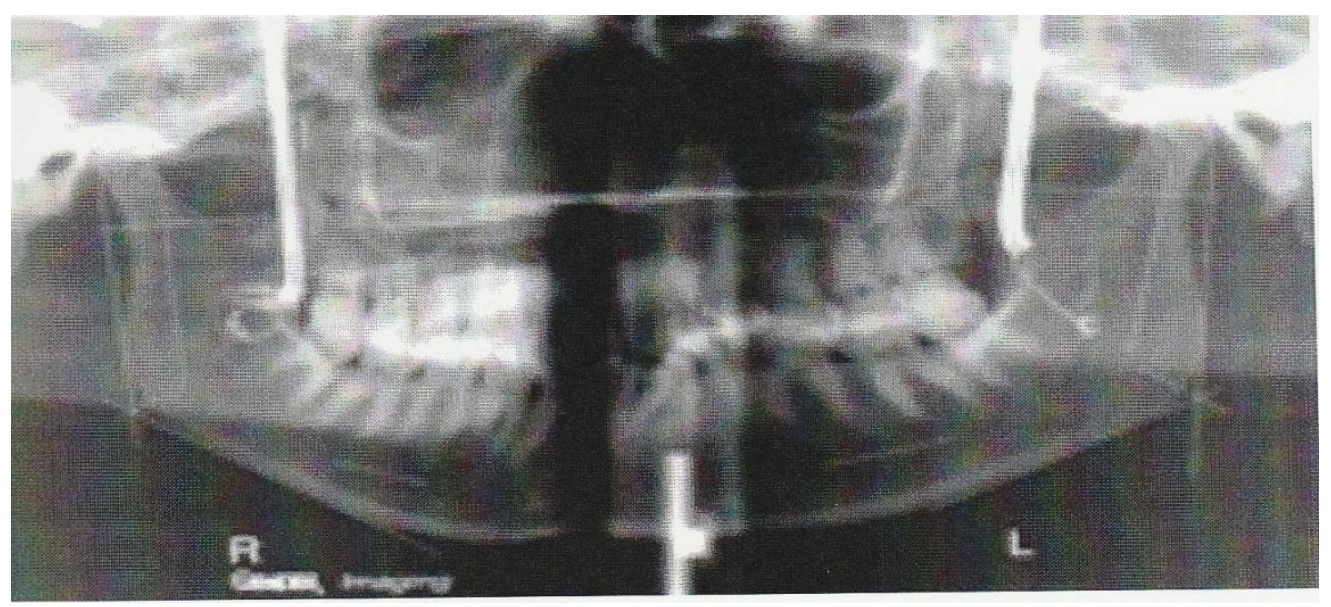

Gambar 3. Gambar panoramic dari tulang tengkorak yang tampak ditempatkan pada posisi yang bergeser

Posisi kedua dari tulang tengkorak bergeser (gambar 3) yang ditempatkan pada bidang midsagital $7 \mathrm{~mm}$ terhadap kelurusan yang ideal. Hal ini kembali menggunakan 7 $\mathrm{mm}$ tanda sementara pada stiker permukaan fasial serta $7 \mathrm{~mm}$ garis sementara/khayal di sepanjang atap tengkorak.5

Ketidaksesuaian terbesar dalam gambaran panoramik terdapat pada pengukuran horisontal posisi tulang tengkorak yang bergeser. Deviasi rata-rata dari jarak perkiraan gonion-foramen mentalis adalah lebih 4,6 mm di sisi kiri, dan kurang 5,6 $\mathrm{mm}$ di sisi kanan. Karena anatomi sisi kiri berubah lebih ke medial sehubungan dengan bidang fokal, maka tulang tengkorak tampak membesar. Sebaliknya, anatomi sisi kanan berubah ke lateral sehubungan dengan bidang fokal dan dengan demikian tampak mengecil dalam gambaran panoramik. Ketidaksesuaian pengukuran horisontal yang lebih besar daripada pengukuran vertikal tidak dapat dipastikan karena perbedaan pembesaran horisontal/vertikal dihasilkan oleh gerakan horisontal yang terbaca pada unit panoramik dan dipengaruhi oleh sejumlah faktor meliputi radius antara bidang fokal dan pusat rotasi sesuai dengan jarak sumberreseptor dan sumber-bidang fokal.5

Kebanyakan unit panoramik memberikan spesifikasi sebagaimana faktor pembesaran pada bidang fokal image layer (pergerakan resiprokal dari sumber sinar-x dan reseptor gambar mengelilingi titik atau bidang pusat). Sebagai tambahan, lokasi bidang fokal ditentukan dengan unit sinar-X yang dihasilkan. Pengaturan bentuk bidang fokal terbatas atau tidak ada pada kebanyakan unit sehingga sulit untuk 
mendapatkan posisi anatomi pasien yang tepat dengan bentuk dan posisi pada bidang fokal sehingga menghasilkan penggambaran radiografi anatomi yang menyimpang.5

\section{PEMBAHASAN}

Dari penelitian di atas diketahui bahwa radiografi panoramik kurang akurat untuk mendeteksi ketidaksimetrisan mandibula karena kesalahan teknis, namun dapat digunakan untuk mengevaluasi ketidaksimetrisan vertikal posterior mandibula.

Keuntungan dari radiografi panoramik adalah menampakkan struktur tulang wajah dan gigi secara luas, memberikan dosis radiasi yang rendah terhadap pasien, memudahkan pemeriksaan bagi pasien, dapat digunakan pada pasien yang tidak dapat membuka mulut, dan waktu yang dibutuhkan singkat hanya sekitar 3-4 menit.1 Sedangkan kekurangan dari radiografi panoramik adalah tidak dapat menampakkan struktur intraoral secara detail seperti pada gambaran radiografi periapikal, termasuk dalam mendeteksi lesi karies yang kecil, struktur marginal periodonsium dan penyakit periapikal.2 Selain itu, dapat memberikan pembesaran yang tidak sama dan gambaran yang distorsi.

\section{SIMPULAN}

Untuk mengetahui ketidaksimetrisan mandibula dapat digunakan hasil gambaran radiografi panoramik. Radiografi panoramik kurang akurat untuk mendeteksi ketidaksimetrisan mandibula apabila disebabkan karena kesalahan teknis, namun dapat digunakan untuk mengevaluasi ketidaksimetrisan vertikal posterior mandibula dan yang berhubungan dengan kelainan skeletal.

\section{DAFTAR PUSTAKA}

1. Kambylafkas P, Murdock E, Gilda E, Tallents RH, Kyrkanides S. Validity of panoramic radiographs for measuring mandibular asymmetry. Angle Orthodontist 2005; 76: 388-93.

2. White SC, Pharoah MJ. Oral radiology principles and interpretation. 5th ed. New York: Mosby; 2004. pp.191, 2001.

3. Chuenchompoonut V, Ida M, Honda E, Kurabayashi T, Sasaki T. Accuracy of panoramic radiography in assessing the dimensions of radiolucent jaw lesions with distinct or indistinct borders. Dentomaxillofac Radiology 2003; 32: 80-6.

4. Legrell PE, Nyquist $\mathrm{H}$, Isberg A. Validity of identification of gonion and 
antegonion in frontal cephalograms.

Angle Orthodontist 2000; 71: 157-64.

5. Lester WS, Ludlow JB, Bailey LJ,

Hershey HG. Accuracy of measurements of mandibular anatomy and prediction of asymmetry in panoramic radiographic images. Dentomaxillofac Radiology 2005; 34:

343-9 